\title{
Study on the synergy of Theatre Pedagogy and Philosophy for Children: A multi-disciplinary approach
}

\author{
Evi Mamalia, Simos Papadopoulos ${ }^{b}$
}

\begin{abstract}
This study explores the reasons for which theatre pedagogy as practiced through drama inquiry is highly compatible with philosophical inquiry as practiced in a community of inquiry. After clarifying the way in which theatre and philosophy can be practiced in an educational context, common elements of drama and philosophical inquiry are examined in terms of epistemology and method. As it is suggested that a number of skills and attitudes can be traced in both drama and philosophical inquiry, there follows an elaborated presentation of such points of relevance. The study concludes that a synergy of drama and philosophical inquiry may not only be feasible, but also highly productive, as there are common aims and principles, which provide a basis for applying effectively a model of philosophical inquiry assisted by drama inquiry.
\end{abstract}

Keywords: Theatre pedagogy, philosophy for children, epistemological dimensions, synergy, physicality, thinking skills

\section{Introduction}

The relationship between theatre and philosophy has been studied in various ways, with the main question being how philosophy is linked to the text of a theatrical play. Indeed, a theatrical text can be the starting point of a philosophical question, and vice versa, "aporein" can become a starting point for the creation of a work, where the theoretical universe becomes representable. Synthesizing theatre and philosophy may seemingly be a difficult task, yet there are reasons which substantiate that such a venture is feasible and effectual.

This study attempts to explore the relationship between theatre and philosophy in an educational context. This interdisciplinary approach of learning concerns the synthesis, in particular, of theatre pedagogy - as technically expressed by the method of drama inquiry - with a program

a. Democritus University of Thrace - Department of Primary Education. evima7@gmail.com

b. Democritus University of Thrace. of philosophical inquiry, as could be applied in the context of school education. This synthesis starts from the existence of a common denominator in the two objects, that of inquiry. Without disclaiming its artistic aspect, theatre in this case puts representation and expression in the service of gaining knowledge. This knowledge is understood as temporary and subject to change, which makes it compatible with the intention of a philosophical inquiry program, a condition of which is the elimination of certainties and a consent for openness. Openness, in turn, is a concept inherent in inquiry; it is identical both to the acceptance of multiple interpretations of the issues under investigation and to the moral attitude and willingness of the participants to be receptive to being shifted from one mental position to another provided it is reasonably valid and sufficiently documented. Below, the points of convergence between theatre pedagogy and philosophical inquiry are selected and examined, while it is explored whether and to what extent their synthesis would be possible as well as how it could be beneficial to those who would take part in a program combining them both. 
Outlining the presence of a philosophical inquiry program within the framework of education

Philosophy, initially, relates to a mental and a psycho-emotional state in which the individual feels awkward, puzzled or surprised and finally curious as to why things happen the way they do. It is a sense of discontent that leads the individual to pose questions ("aporein") and embark on an exploration of ideas, concepts, definitions, reasons, theories with the intention of elucidating logically vague points in thinking and reaching closer to what could temporarily called "truth". Thus, philosophy is not a subject presenting the complete and definite truth about life and the world; rather, it is an activity (Warburton, 2010) that helps the individual illuminate questions holding a critical stance towards the content and the process of thinking.

When we talk about philosophy within an educational framework, it is necessary to clarify how this is conceived. We must, therefore, make a double distinction. In this case, adopting philosophy in an educational context does not mean teaching it as a subject in a knowledge-based approach; nor does it mean downgrading it by using its individual thinking skills in order to serve learning objectives and thus instrumentalizing it. The first one draws philosophy back to aiming at obsolete educational goals and the second one leads to its fragmentation and to a distancing from its essence. Both deprive it of a key element, the èthos of philosophizing (Theodoropoulou, 2006). It should be noted that implementing critical thinking programs, which align with philosophical thinking goals to a great extent, does not serve the aims of an independent program of philosophical inquiry. To conduct a comprehensive program of philosophical inquiry means not only cultivating the relevant set of thinking skills, but also a relevant attitude regarding philosophizing. Consequently, this means, that both educators and students take a critical, thoughtful attitude towards what is happening, as well as towards their role (Theodorides, 2010). Therefore, a program of philosophy within the framework of education that has autonomy and is compatible with the demands of this subject encourages aporein and the systematic formulation of questions, seeks for the analysis of concepts and is applied by method, not for the purpose of teaching the history of philosophical ideas but for connecting abstract concepts of philosophy with the experiences of life itself (Murris, 2000). The way in which the "openness" required by philosophical inquiry is perceived plays an important role in whether its essence is realized or not. The moral relativism which this "openness" involves must be put to the test of systematic, critical scrutiny in order to establish the validity of the positions formulated, so that those which are reasonably invalid or unrelated to the subject under investigation are pinpointed (Haynes \& Murris, 2011).

Such a presence of philosophy within the educational context can take the form of a "philosophy for children program". In this context, children have the opportunity to think critically and creatively regarding contents of different subjects, explore the way these interconnect with each other as well as reflect upon the meaning of the process itself. A "philosophy for children program" involves two key elements.

The first one is dialogue in a systematized version in contrast with conversational speech. This means that the interactive inquiry on an issue does not remain a simple exchange of views. It is a process of co-building a "truth" by the participants based on the foundations of logic, while it is clear that the "truth" in question involves a temporality and, therefore, it does not leave any room for absolute declarations. Within this dialogue-centered context an intention to systematize thought develops, with dialectic being the predominant way. The participants, thinking philosophically, explore in the first phase the main concept that is inherent in the original question and its definitions and submit pre-existing beliefs about it. Then, in the process of dialectical negotiation, some judgements take the form of acceptable generalizations and vice versa, so that a system of thought with reflective function is formed (Lipman, 2006).

The second element is the integration of emotion as a functional part of philosophical inquiry in order to assist cognition. As emotions are forms of judgements, they are involved in the assessment of situations by even being carriers of personal meanings, ambiguity and of modality of per- 
ception. The participant of a philosophical inquiry exercises in using emotions - his own and others' - to deepen his thinking, recognizing which have an effect on the formulation of disprovable claims and unsubstantiated beliefs (Sharp, 2008). Taking into account emotions in the process of thinking logically during inquiry leads to a kind of thinking that puts empathy in the service of reasonableness, a fundamental demand, especially when it comes to ethical issues.

Epistemologically, inserting philosophy in the educational context in a self-contained way is consistent with constructivist logic. Reorganizing a student body in a community of philosophical inquiry that explores a question and the concepts it consists of, refers to the principles of constructivism about the acquisition of knowledge. According to them, humans cannot understand and assimilate the ready-made information unless they link it to experience (Schunk, 2010). Thus, knowledge arises from the social interaction of man and cooperative activity with his environment. In essence, within the community of philosophical inquiry, whatever happens supports the position of social constructivism: a systematized negotiation of plurality in the interpretation of reality and the concepts it is founded on. The community itself becomes the site of this intersubjective search, embracing a view of reality as an open, dynamic field (Borisov, 2014). In this field another negotiation is carried out: that between the student and the content of the disciplines per se. Here, the educator plays a key role. Adopting the principles of constructivism guides the student to connect the contents with his experiences. The ultimate goal is for the student to develop with the assistance of the educator the appropriate skills and attitudes that will help him handle contents more actively, formulate and test hypotheses and attribute a personal meaning to the process. In the community of philosophical inquiry the educator does not bias students so that they become favorably disposed towards contents in advance, taking for granted their "truth". On the contrary, authentic learning identifies with self-correction, that is to say, with a restructuring of thoughts, feelings and actions, and then with the possibility of self-verification, in other words by passing to a stage of confirmation of changes by experience itself (Gregory, 2002). In both cases, the key is to form an active thinking that puts the pre-established ideas to a test and develops independent judgment through a collaborative framework.

\section{Theatre Pedagogy: Points of relevance to Philos- ophy for children}

The same epistemological background establishes theater pedagogy. Referring mainly to the method of drama inquiry, the acquisition of new knowledge is performed in a constructivist way. too. Improvisations and role play are only a few practices through which ideas and concepts are approached experimentally and exploratory. What differs is the way in which inquiry is conducted; in the case of theater, an experiential code is adopted. Through multiple exploratory attempts pre-existing knowledge is enacted anew, tested and re-examined. In this way, theater pedagogy moves away from the empirical example of recognizing "objective truths" that exist independently of the thinking person. Knowledge is problematized; it becomes an object for collaborative processing. Meaning arises through time and space; at the same time, this practice shapes the situation and the context, making our imaginary knowledge seemingly true (Rasmussen, 2010). Through the constructed experience of the theatrical-pedagogical laboratory the new knowledge is incorporated into the already existing belief system until it is challenged again and re-investigated.

In theatre pedagogy, a set of drama techniques is adopted that activates thinking and philosophical inquiry. Thinking activity is carried out on the basis of a creative code and takes place inside an aesthetic environment, sometimes shaped in artistic terms. The use of imaginary stories, as well as emotional and physical expression, are very powerful tools in the effort to explore questions and attribute meaning. Thought tracking, perspective taking, conflicting thoughts, image theatre and verbalizing emotions add multiple meanings and strengthen the information that comes from the thinking person (Papadopoulos, 2010). The examination of claims and the testing of ideas through more than one prism bring the student experien- 
tially in contact with the concept of subjectivity and relativism. The externalization of an internal monologue, asking questions, the inductive reasoning after a series of individual experiences, the production of associations as informal reasoning, an empathetic inference, are all just some of the thinking skills involved in embodied philosophical inquiry during theatrical improvisation. The aforementioned give the participants the opportunity to gain a sense of criterion and seek for more correct judgments through arguments. All this constructive and creative exploration of ideas through imaginary scenarios, of beliefs and choices to act, of the reasons things happen the way they do on different occasions, is knowledge transferred to real life (D'Olimpio, 2004).

In addition, physicality is associated with higher order cognitive functions in various ways. It is characteristic that logic has an embodied basis and is linked to neural networks related to sensory motor mechanisms, as well as emotion (Lakoff \& Johnson, 1999), two dominant parameters in theatre. In addition, physicality is involved in the process of perception and thinking due to image schema, a concept that abolishes the dualistic logic that separates the body from the mind. Among others, Dewey and Merleau-Ponty supported that body and mind are parts of a whole, created by the interactions of an organism with its environment, and are simultaneously physical and mental (Johnson, 2017). Consequently, what is called "mind" essentially has an embodied basis, since thinking, values and symbolic function arise from structures of perception, movement and other organic processes. As Johnson points out, image schemas are repetitive patterns structured on the basis of our sensory-motor and emotional experience, which play a key role in the rendering of meaning and in the logical explanation of our experiences, while they are also involved in the process of inference associated with abstract thinking (Johnson, 2017). The existence and function of image schemas is what connects abstract thinking and higher order cognitive processes of philosophical inquiry with physicality offered by the theatrical element, proving not only that these two intertwine, but also that action - in terms of theater - further activates thinking.
Theatrical experience within the educational context provides the student with more information, brings him in contact with the stories of others increasing knowledge for the world and familiarizes him with the multiple modality of "being" and "thinking". Due to its experiential nature, but also due to the fact that it activates the participant to the maximum degree - both as an actor and through the role of observer who interprets what is seen (Reason, 2008) - it serves as a field of embodied thinking. Through imagination, the student is given the opportunity to come from the safe position of the role face to face with life situations, to reflect on them and to connect them with the "big questions". His active involvement and reflection on actions and values of a character extends to an inquiry on the actions and values that he himself adopts and then to the critical examination of the values and norms of society (D 'Olimpio, 2017).

A theatrical workshop can become a field of philosophical inquiry through body and experience. Physical expression and what is subject to the senses act as a mediating action so that, with the help of emotions, we ascend gradually to the conceivable, to the abstract, to the realm of concepts (Boeglin, 2004). It is the experiential that attributes form to the idea in an embodied version of philosophizing, making the person acquire consciousness of the mental but also, mutually, transforming the mental into an experience. The new experience generates new ideas, which are incorporated in an equally new, intensive dialogue.

\section{On the feasible and beneficial synergy between Theater Pedagogy and Philosophy for Children}

The object of philosophy - when it is carried out as a program of philosophical inquiry in an educational context - and of theater - when it adopts its pedagogical dimension - present points of convergence. For this reason, linking them together into a single, operating system is considered technically feasible and pedagogically beneficial. The unified version of these two objects could take the form of an enhanced philosophy program for/ with children in the context of education, in which philosophy and theater work together through a relationship of complementarity and mutual rein- 
forcement. In particular, the high degree of compatibility between philosophical inquiry in educational context and drama inquiry in the context of theater pedagogy can be summarized in the following points:

- There is a common orientation and a common place: problematization and negotiation. In both theater pedagogy and philosophical enquiry, the themes, ideas and concepts are problematized. Due to their exploratory nature, nothing is considered to exist in a definite form and no starting point is accepted as a definite position. Each one through a different code, philosophy through doubt and theater through movement-action, calls certainties into question. Problematization is followed by negotiation of ideas and claims. In the experiential space of a stage action and in a philosophical inquiry, a negotiation of concepts, ideas and views takes place. These, in turn, produce new data, spatial, emotional and ideological shifts that lead to new views on the issues under investigation.

- Theatre pedagogy and philosophical inquiry are also related through the concept of mediation. What unfolds in a theatrical scene is a mediation between the abstract nature of philosophical ideas and the specific one proposed by theater (Pefanis, 2016). The abstract is embodied in the stage space as philosophical thinking takes the form of a dialectic of ideas and "truth" through role play. The actor identifies with the thinker and vice versa, in an intermediate space where abstract ideas are embodied through action, captured through symbols and concretized through material-body codes. The addition of the theatrical element during philosophical inquiry constitutes a choice of extension. The synergy of the two is not limited to formalities about the ontological search. It extends to adding the value element to ideas, inverting hierarchies or deviating from the original idea and re-focusing on related ideas. The participants become speakers and listeners at the same time, in an event that cannot be "read" unambiguously, because it does not guarantee any absolute truth at the end.

- A third connecting point is the interest in exploring otherness. In both philosophical and drama inquiry, the search for the truth of the other, as well as the search for the truth of the self through the other, are key points of interest. What could be articulated as philosophical thinking through a theatrical performance it takes off its theoretical aspect and is invested as dialogue between acting roles (without of course omitting the possibility of a revealing monologue). The exploration of the alien nature and of "the unfamiliar" is carried out through an organized exchange of ideas, feelings and experiences, in philosophical inquiry by addressing to the gained experience, and in drama inquiry by producing experience through a hypothetical condition.

- The fourth point of connection concerns the mutual work on the investigation of the "truth" - with the temporality that always characterizes this concept in exploratory environments. Especially in view of the extreme nominalist tendency attributed to the post-modern era (Burbules, 2009) - which fragments meanings in communication due to the existence of numerous "idioms", thus questioning concepts such as "truth" - an apprenticeship of an exploratory nature, based on rational principles, is considered necessary, not only for the cultivation of skills, but also as an attitude and mentality of life. Inquiry is the key term in this case, as it states a systematic character based on scientific principles. The dialogical element in inquiry is in line with a concept of thinking such that it connects the person educated through philosophy with reality, a fact that makes it compatible with the essence of philosophy (Theodoropoulou, 2010), promoting the criterion of rationality to assess the appropriateness of propositions or assertions (Leleux, 2008). In theater pedagogy, methods such as drama inquiry, systematize exploration by introducing dialogue into an experiential version, along with the imaginary and emotional condition that extends thinking and 
gives it a sense of laboratory experience. In this way, philosophical inquiry relates to theater pedagogy through a relation of complementarity.

- An additional point of connection is that they presuppose community and "togetherness". That is, both philosophical and drama inquiry, take place within a condition of collectivity, the community of inquiry and the theatrical group respectively. In both cases, there is a sense of interaction - although it is expressed differently in each case - which makes them collaborative communities of inquiry. Both are based on the consent of the participants for the joint construction of the meanings proving the social character of the processes. This presupposes a mutual transcendence of subjective limits and their constant reshaping, as in the field of inquiry the self is experienced as the other, as a "lived otherness". Participants, then, in both cases transition to intersubjectivity, a sense of self as inclusive of the other, an ontological, ethical and normative acceptance that someone is both the self and the other, a system that builds and simultaneously perceives the personal as collective (Kennedy, 2010). The participants in community of inquiry, as well as the members of a theatrical group that co-explore, think collectively and this is accomplished because there is a "social space" that allows them to think with others. After all, thinking, philosophical inquiry, is a fact and not just a set of skills, it is an experience and not just a technique (Kohan, 2002).

- One last point of high relevance between philosophical and drama inquiry is their emancipatory character. Both are based on a pedagogical intention to turn the participants into independent thinkers. Starting from the collaborative nature of the theatre group and the community of philosophical inquiry, the ultimate goal is for the participants to ascend to a level of thinking autonomy. Working within an imaginary social space - the community and the theatre group - they are exposed to the alternative approach of things and incorporate it into already existing modes of think- ing. In this way, they move from the "univocal" to multimodality, advocating the inclusion of the other in the self. The multiple views of things are internalized, together with all they include, thus shaping the corresponding attitude of life. Therefore, in a subsequent phase, the same persons perform the same thinking processes outside the theatre workshop or community of philosophical inquiry, introducing into their lives, among many others, the element of questioning and doubt, rationality and empathetic understanding, imaginary hypothesis and criteria seeking.

Theatre pedagogy students participate in processes in which, through the discreet guidance of an adult, an empowering action coordinator ( $\mathrm{Pa}-$ pageorgiou \& Papadopoulos, 2018), they systematically exercise in mental, psycho-emotional and social skills (Baldwin, 2012). A similar condition applies to those educated through philosophical inquiry; this condition is strengthened, however, by the addition of the multisensory environment and the insertion of the factor of physicality that the synergy with theater can offer. The mental is substantiated through physicality that makes the idea presentable. Synthesizing theater pedagogy and philosophical inquiry offers a new dynamic that arises from their synergy, expanding the potential of each individual object: the "dramatic" test of a question or an ignorance declared from the beginning. By inserting a philosophical idea or a question in different contexts during dramatization, the idea is essentially tested, often resulting in a new series of questions. This function of opening a new field of inquiry is compatible with the function of philosophy. The theatrical presentation of ideas constitutes their depiction in terms of the material and perceptible world, connecting them with their practical dimension. Their experiential negotiation relativizes meanings. Physicality, such as gestures, facial expressions, posture and body position in space, enhances information, not previously accessible to the senses. Examining philosophical questions through different hypothetical scenarios reintroduces doubt, leading to seeking for new definitions of the concepts that make them up. By attributing to the ideas, through 
the theatrical element, a material equivalent and by approaching them with the help of emotion, inductive reasoning gains new possibilities, as it draws new information from individual events that highlight a multifaceted version of these ideas.

The synergy of theater pedagogy and philosophical inquiry in an educational context is in itself a position and a philosophical "gesture" with a specific pedagogical intention. It opens a field where philosophical inquiry becomes an experience in educational and artistic terms. The artistic aspect provides high potential of inclusion - mainly through creative expression, playfulness and storytelling - mitigating participant inequalities and establishing the spirit of participatory democracy, thus making this synergy compatible with the broader demands of social pedagogy, too (Mylonakou-Keke, 2013). It multiplies and deepens thinking and reflective "acts" in a "simulated" environment that prepares participants for "real" life. Within the experiential field of theater, philosophy acquires the ability to take on its practical aspect and function, one that is connected with everyday human condition. This opens up for philosophy a perspective to record in the theatrical, experiential field its very essence, through choice, behavior, experience, negotiation by means of role play and the hypothetical condition. It is this synergy that ensures the transition from the hypothetical to the realistic scenario and thus the transition to a life performance, a kind of performance art outside the stage, in the realm of real life.

\section{References}

Baldwin, P. (2012). With Drama in Mind. Real Learning in Imagined Worlds. Bloomsbury Publishing. Boeglin, M. (2004). Philosopher avec le corps. Cahiers Pedagogiques, No 432.

Borisov, S. (2014). Ideas of Constructivism in Philosophy of Education: from Ontology to Phenomenology. Life Science Journal, Vol. 11. No 11.

Burbules, N. (2009). Postmodernism and Education. in Harvey Siegel (ed.), The Oxford Handbook of Philosophy of Education. Oxford University Press.

D’Olimpio, L. (2004). Drama and Philosophy: Lan- guage, Thinking and Laughing Out Loud! Applied Theatre Researcher, No5.

D'Olimpio, L. (2017). Playing with Philosophy: Gestures, Life Performance, P4C and an Art of Living. Educational Philosophy and Theory. Vol 49. Issue 13.

Gregory, M. R. (2002). Constructivism, Standards, and the Classroom Community of Inquiry. Educational Theory, Vol 52. Issue 4.

Haynes, J. \& Murris, K. (2011.) The Provocation of an Epistemological Shift in Teacher Education through Philosophy with Children. Journal of Philosophy of Education. Vol. 45. Issue 2.

Johnson, M. (2017). Embodied Mind, Meaning and Reason: How our Bodies Give Rise to Understanding. University of Chicago Press.

Kennedy, D. (2010). Philosophical Dialogue with Children: Essays on Theory and Practice. Edwin Mellen Press.

Kohan, W.O. (2002). Education, Philosophy and Childhood: The Need to Think an Encounter. Thinking. The Journal of Philosophy for Children. Vol. 16. Issue 1.

Lakoff, G. \& Johnson, M. (1999). Philosophy in the Flesh: The Embodied Mind and its Challenge to Western Thought. Basic Books.

Leleux, C. (2008). Apprendre a penser des 5 ans a l'epreuve du modele de Matthew Lipman? In C. Leleux (Ed.), La Philosophie pour Enfants. Le Modele du Matthew Lipman en Discussion (pp. 117-129). De Boeck Superieur.

Lipman, M. (2006). Thinking in Education. Ekdoseis Patakis [in Greek].

Murris, K. (2000). Can Children Do Philosophy? Journal of Philosophy of Education. Vol. 34. No2.

Mylonakou-Keke, I. (2013). Social Pedagogy. Theoretical, Epistemological and Methodological Dimentions. Ekdoseis Diadrasi [in Greek].

Papadopoulos, S. (2010). Theatre Pedagogy. Athens [in Greek].

Papageorgiou, K. \& Papadopoulos, S. (2018). Theatre Pedagogy and the Distal Method in Psycho-Social Development. Applied Pedagogy. Vol 9 [in Greek].

Pefanis, G.P. (2016). Adherents and Philosophers of Theatre. An outline of Theatre Philosophy. Ekdoseis Papazisis [in Greek].

Rasmussen, B. (2010). The 'Good Enough' Drama: 
Reinterpreting Constructivist Aesthetics and Epistemology in Drama Education. Research in Drama Education: The Journal of Applied Theatre and Performance. Vol. 15. Issue 4

Reason, M. (2008). Thinking Theatre: Enhancing Children's Theatrical Experiences through Philosophical Enquiry. Childhood and Philosophy. Vol. 4. No 7.

Schunk, D. H. (2010). Learning Theories: An Educational Perspective. Ekdoseis Metaixmio [in Greek]. Sharp, A. M. (2008). Philosophizing about our emotions in the classroom. Proceedings of the XXII World Congress of Philosophy. Vol 27.

Theodoridis, A. (2012). The possibility of educating a critically thinking person and the curriculum of Greek primary education Dia-LOGOS. Vol 2 [in Greek].

Theodoropoulou, E. (2006). Who thinks better? Philosophy: The phantom in the machine. Childhood and Philosophy. Vol 2. No 3.

Theodoropoulou, E. (2010). The philosophical bank of the dialogical stream in education. Conference Minutes: "Philosophical Dialogue in the Classroom", (ed). G. Tzavaras [in Greek].

Warburton, N. (2010). Philosophy: The Basics. Ekdoseis Arsenidis [in Greek]. 